\title{
Changes in Total Body Water in Infants Receiving Total Intravenous Nutrition
}

\author{
Theodore Z. Polley, JR., M.D., Jon W. Benner, M.D., Anders Rhodin, M.D., \\ William H. Weintraub, M.D., and Arnold G. Coran, M.D. ${ }^{1}$ \\ Section of Pediatric Surgery, Mott Children's Hospital and University of Michigan Medical School, \\ Ann Arbor, Michigan 48109
}

Presented at the Annual Meeting of the Association for Academic Surgery, Cleveland, Ohio, November 12-15, 1978

\begin{abstract}
Using deuterium oxide dilution technique, the total body water changes of five infants maintained on total parenteral nutrition have been determined. While average weight gains of from 14 to 53 $\mathrm{g} /$ day were documented, there were decreases in percentage total body water from 13 to $50 \%$. These data taken together support tissue accretion rather than water retention as the mechanism of weight gain in the long-term, large-volume, total parenteral nutrition of these infants
\end{abstract}

\section{INTRODUCTION}

The use of large-volume central and peripheral total parenteral nutrition has gained increased acceptance and wide application in the fields of neonatology and pediatric surgery [9]. With this therapy weight gain superior to oral caloric supplementation has been demonstrated in lowbirth-weight infants [5]. In addition, ample weight gain has been demonstrated along with satisfactory wound healing in the postoperative pediatric and adult patient unable to receive oral alimentation for a prolonged period of time. The nature of this weight gain, however, whether water retention or increase in body mass, is still debated. Brans et al. $[1,2]$ using the technique of corrected bromide space to calculate extravascular water suggest that water retention accounts for weight gain, while Pildes et al. [16] and Driscoll et al. [5] support increase in body mass. Prior to previous publication from this laboratory [17] no total body water (TBW) studies in infants had been carried out to explore this question.

While the tritiated water dilution tech-

\footnotetext{
${ }^{1}$ To whom requests for reprints should be addressed: F 7516 Mott Children's Hospital, University of Michigan Medical Center, Ann Arbor, Mich. 48109.
}

nique has been used in adults to study water balance, its use is ethically precluded in infants due to the radiation hazard of the isotope. On the other hand, the deuterium oxide dilution method, while cumbersome, is safer and well suited for determination of total body water content. Accuracy comparable to mass spectrophotometry adds to the attractiveness of the technique.

The following study was undertaken to determine total body water content and its contribution to weight gain in infants receiving high-volume peripheral total parenteral nutrition.

\section{MATERIALS AND METHODS}

Five infants with initial weight ranging from 1600 to $2550 \mathrm{~g}$ hospitalized in Holden Neonatal Intensive Care Unit of the University of Michigan Mott Children's Hospital were studied for periods of 2 weeks to 4 months. The patient group included two premature males, one full-term male, and two full-term females. During the study period the patients were maintained on peripheral total parenteral nutrition combining solutions of $2 \%$ amino acids, $12 \%$ glucose, and $10 \%$ fat emulsion (Intralipid, Cutler) administered at a rate of $140-160 \mathrm{cc} / \mathrm{kg} /$ day and $100-110 \mathrm{cal} / \mathrm{kg} / \mathrm{day}$. 


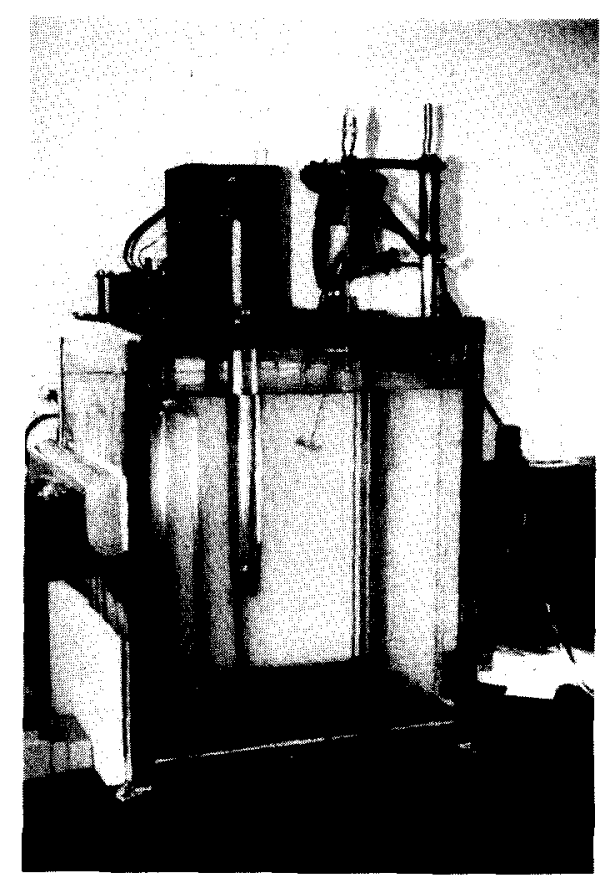

FIG. 1. Photograph of falling drop chamber used for determination of deuterium oxide concentration.

Total body water was determined at intervals varying from 1 to 4 weeks using the deuterium oxide dilution technique described by Schloerb et al. [18, 19]. The study was performed only after receiving informed consent of parents and was conducted in accordance with standards established by the Human Use Committee. This technique is based on derivation of a standard curve relating known concentration of deuterium oxide (vol\%) to length of time (to $0.1 \mathrm{sec}$ ) required for isovolumic drops of double-vacuum-distilled standard solution to fall a constant distance through a column of ortho-fluorotoluene. The apparatus shown in Fig. 1 is designed to maintain the temperature of the water bath surrounding the falling drop chamber within 0.01 of a degree centigrade. This is critical to the accuracy of the procedure. Multiple determinations are made for each standard point to achieve precision within $2 \%$.

Serum samples $(1.5 \mathrm{cc})$ are obtained, centrifuged, and frozen $2.5 \mathrm{hr}$ after in- travenous administration of a precisely weighed dose of deuterium oxide $(99.7 \%$, Merck).

Prior to administration the $\mathrm{D}_{2} \mathrm{O}$ is sterilized by passage through a series of hospital pharmacy micropore filters. Great care is taken to assure reliable venous access so that none of the isotope is extravasated into surrounding tissues. Following doublevacuum distillation, falling times of these serum distillates are determined and $\mathrm{D}_{2} \mathrm{O}$ concentration $(X)$ is calculated by interpolation from the standard curve according to the following formula,

$$
X=\frac{\frac{1}{E_{\mathrm{x}}}-\frac{1}{t_{\mathrm{s}}}}{\frac{1}{t_{\mathrm{s}^{\prime}}}-\frac{1}{t_{\mathrm{s}}}}\left(s^{\prime}-s\right)+s,
$$

where $X=\mathrm{D}_{2} \mathrm{O}$ concentration of patient serum volume $\% ; E_{\mathrm{x}}=$ falling time of study serum distillate in seconds; $t_{\mathrm{s}}=$ falling time of lower standard distillate in seconds; $t_{\mathrm{s}^{\prime}}$ $=$ falling time of higher standard distillate in seconds; $s=$ deuterium oxide concentration of lower standard in volume percentage; $s^{\prime}=$ deuterium oxide concentration of higher standard in volume percentage. Total body water can then be calculated given the known weight of injected $\mathrm{D}_{2} \mathrm{O}$, serum concentration of $\mathrm{D}_{2} \mathrm{O}$, and established (Schloerb et al. [18, 19]) $\mathrm{D}_{2} \mathrm{O}$ excretion rate of $0.4 \%$ of injected volume over the 2.5-hr equilibration period,

$$
v=\frac{c_{1} v_{1}-c_{\mathrm{u}} v_{\mathrm{u}}}{c_{2}} .
$$

$v$ Total body water in liters (volume of water into which injected deuterium oxide diffuses at equilibrium)

$c_{1}$ Concentration of injected deuterium oxide (0.997)

$v_{1} \quad$ Volume of deuterium oxide injected corrected at $37^{\circ} \mathrm{C}$ (grams of deuterium oxide solution injected divided by its density at $37^{\circ} \mathrm{C}$ $=1.10098 \mathrm{~g} / \mathrm{ml}[3])$ 
$c_{\mathrm{u}} v_{\mathrm{u}} \quad$ Total amount of excreted deuterium oxide from time of injection to time of sampling, $2.5 \mathrm{hr}$ (this represents insensible water loss plus urine loss and has been suggested by Schloerb et al. to equal $0.4 \%$ of injected deuterium oxide $\left.\left(c_{1} v_{1}\right)\right)$

$c_{2}$ Study serum concentration of deuterium oxide at equilibrium ( $X$ from previous formula divided by 100 )

\section{RESULTS}

Average weight gains of $14-53 \mathrm{~g} /$ day were documented in the study patients. Patient 1 (Table 1), an infant with gastroschisis and short bowel syndrome, demonstrated gradual decrease in TBW\% with concurrent weight gain. Figure 2 summarizes the hospital course in great detail including weight $(\mathrm{kg})$, intravenous plus oral intake, and crown-heel length. Changes in patient's TBW\% are plotted along with literature control values (Friis-Hansen et al. [11], Friis-Hansen [10, 12, 13], Flexner et al. [9], Edelman et al. [7], and Osler [15]). Similarly patient 2 with duodenal atresia, patient 3 with gastroschisis, patient 4 with perforated
TABLE 1

Total Body Water Changes during Peripheral Hyperalimentation

\begin{tabular}{cccc}
\hline $\begin{array}{c}\text { Age } \\
\text { (weeks) }\end{array}$ & $\begin{array}{c}\text { Weight } \\
\text { (kg) }\end{array}$ & $\begin{array}{c}\text { Total } \\
\text { body water } \\
\text { (liters) }\end{array}$ & $\begin{array}{c}\text { Total } \\
\text { body water } \\
\text { (\% body wt) }\end{array}$ \\
\hline $\begin{array}{c}\text { Patient 1 } \\
3\end{array}$ & 1.88 & 1.450 & 77.1 \\
4 & 2.24 & 1.537 & 68.6 \\
7 & 2.60 & 1.699 & 65.4 \\
11 & 2.62 & 1.591 & 60.7 \\
14 & 2.70 & 1.739 & 64.4 \\
17 & 2.80 & 1.694 & 60.5 \\
Patient 2 & & & \\
1 & 2.59 & 1.842 & 71.0 \\
2 & 2.78 & 1.603 & 57.6 \\
Patient 3 & & & \\
1 & 2.40 & 1.994 & 83.0 \\
2 & 2.92 & 1.782 & 61.0 \\
Patient 4 & & & \\
1 & 1.60 & 1.641 & 100.0 \\
4 & 2.52 & 1.892 & 75.0 \\
16 & 3.00 & 1.597 & 53.0 \\
17 & 3.16 & 1.264 & 40.0 \\
Patient 5 & & & \\
3 & 2.59 & 2.460 & 95.0 \\
4 & 3.06 & 2.800 & 91.4 \\
5 & 2.86 & 2.230 & 79.0 \\
\hline
\end{tabular}

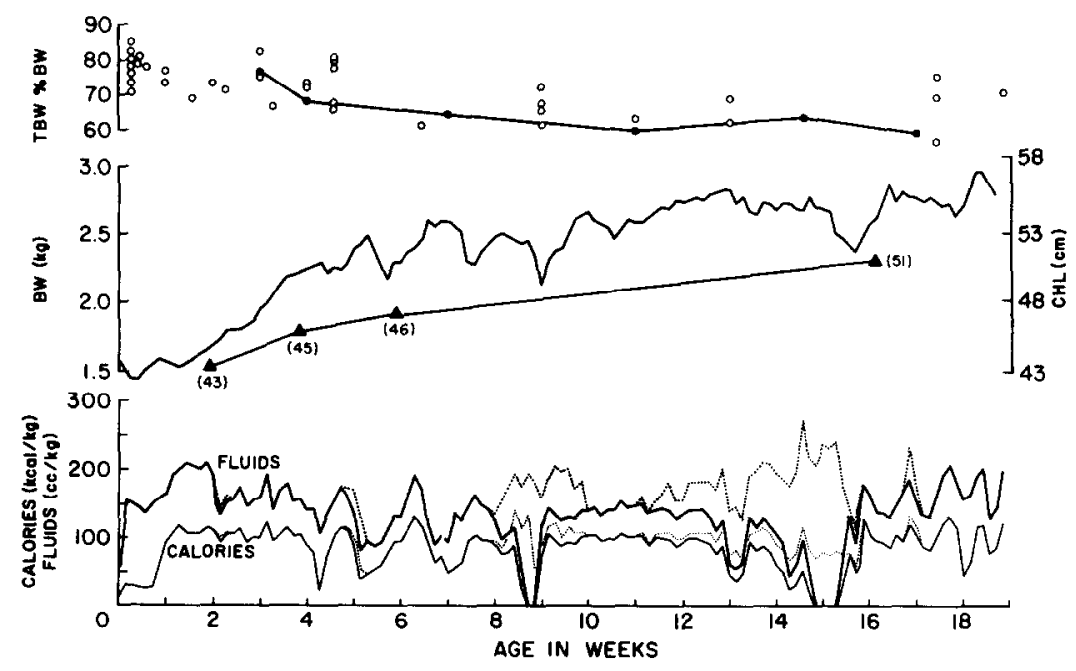

FIG. 2. Graph demonstrating total body water (\% body wt) changes in patient 1 during 17 weeks of parenteral nutrition. The graph also depicts body weight changes and length changes in the infant. BW, body weight; TBW, total body water; $O$, normal TBW measurement from the literature;

$\bullet$, TBW measurement in study patient; $\triangle$, crown-heel length (CHL); — intravenous intake; ..., oral supplementation. 
necrotizing enterocolitis and biliary cirrhosis, and patient 5 with omphalocele demonstrate decrease in TBW\% (71-57\%, $83-60 \%, 100-40 \%, 95-79 \%$ ) with concomitant increase in weight. It should be noted that the course of patient 4 was complicated by congestive heart failure and respiratory distress.

\section{DISCUSSION}

Deuterium oxide is ideally suited for the study of total body water changes in infants. It lacks the exended half-life of the radioactive tritiated water and is distributed homogeneously throughout the body within a short period of time following intravenous or subcutaneous administration. In addition, it is totally nontoxic in the range of serum concentrations achieved. The acceptability of the accuracy of the falling drop method has been underscored by Friis-Hansen [13] who notes only $2 \%$ variation in multiple simultaneous sampling studies. The dynamics and rates of excretion have been carefully determined by Schloerb et al. [18, 19]. Moreover, Schloerb et al. [18] have shown agreement of within $1 \%$ in analysis of standard solutions with both the falling drop and mass spectrophotometric techniques. Of course, this depends on meticulous technique in weighing of standard and injected sample, reliable venous access, accurate patient weight, avoidance of contamination during storage and double-vacuum distillation, constant size of drops used in falling drop chamber, and careful control of chamber temperature. The 1-2\% error in overestimation of TBW, due to exchange of deuterium with labile hydrogen of carbohydrate and protein, is offset by a probably incomplete equilibration of the small amounts of water in the gastrointestinal tract and bone.

While the total body water value of $100 \%$ in patient 4 is obviously not possible strictly speaking, given the prematurity of the infant, existence of cardiac failure, and established error of TBW determination, this value may be more readily accepted. The value of $40 \%$ at 17 weeks in the same patient is spurious, most likely because of inaccuracy of the recorded weight.

Many techniques including desiccation studies, radioactive isotope dilution, and spectrophotometric and falling drop methods of nonradioactive isotope detection have been used to define normal total body water composition of the fetus (94\%) and newborn term infant (78\%). However, while $\mathrm{N}_{2}$ balance studies such as that of Driscoll et al. infer real weight gain in infants on total parenteral nutrition, to our knowledge the $\mathrm{D}_{2} \mathrm{O}$ dilution technique has never becn applied to serial determinations of TBW in order to more precisely define the contribution of water retention to weight gain. Our data showing weight increase along with serial decrease in TBW\% support tissue accretion as the source of weight gain during high-volume peripheral hyperalimentation. Additional patients are presently being studied to confirm these findings in a much larger series of infants.

\section{REFERENCES}

1. Brans, Y. W., Sumners, J. E., Dweck, H. S., and Cassady, G. Feeding the low-birth-weight infant: Orally or parenterally? I. Preliminary results of a comparative study. Pediatrics 54: 15, 1974.

2. Brans, Y. W., Sumners, J. E., Dweck, H. S., Barley, P. E., and Cassady, G. Feeding the lowbirth-weight infant: Orally or parenterally? II. Corrected bromide space in parentcrally-supplemented infants. Pediatrics 58: 809, 1976.

3. Chang, T. L., and Tung, L. H. The density of heavy water between $25^{\circ}$ and $100^{\circ} \mathrm{C}$. Chinese $J$. Phys. (Taipei) 7: 230, 1949.

4. Cruise, M. D. A longitudinal study of the growth of low birth weight infants. I. Velocity and distance growth, birth to 3 years. Pediatrics 51: 620, 1973.

5. Driscoll, J. M., Heird, W. C., Schullinger, J. N., Congaware, R. D., and Winters, R. W. Total intravenous alimentation in low-birth-weight infants: A preliminary report. J. Pediatr. 81: 145, 1972.

6. Dweck, H. S., Saxon, S. A., Benton, J. W., and Cassady, G. Early development of the tiny premature infant. Amer. J. Dis. Child. 126: 28, 1973.

7. Edelman, I. S., Harley, N. B., Schloerb, P. R., Sheldon, D. B., Friis-Hansen, B. J., Stoll, G., and Moore, F. D. Further observations on total body water: I. Normal values throughout the life span. Surg. Gynecol. Obstet. 95: 1, 1952. 
8. Filler, R. M., and Coran, A. G. Total parenteral nutrition in infants and children: Central and peripheral approaches. Surg. Clin. North Amer. 56: $395,1976$.

9. Flexner, L. B., Wilde, W. S., Proctor, N. K., Cowie, D. B., Vosburgh, G. J., and Hellman, L. M. The estimation of extracellular and total body water in the newborn human infant with radioactive sodium and deuterium oxide. J. Pediatr. 30: 413, 1947.

10. Friis-Hansen, B. J. Body composition during growth: In vivo measurements and biochemical data correlated to differential anatomical growth. Pediatrics 47: 264, 1971.

11. Friis-Hansen, B. J., Holliday, M., Stapleton, T., and Wallace, W. M. Total body water in children. Pediatrics 7: 321, 1951.

12. Friis-Hansen, B. J. Changes in body water compartments during growth. Acta Paediatr. Scand. (Suppl.) 46: 110, 1957.

13. Friis-Hansen, B. J. Body water compartments in children: Changes during growth and related changes in body composition. Pediatrics 28: 169, 1961.
14. Lubchenco, L. O., Hansman, C., and Boyd, E. Intrauterine growth in length and head circumference as estimated from live births at gestational ages from 26 to 42 weeks. Pediatrics 37: 403, 1966.

15. Osler, M. Body water of newborn infants of diabetic mothers. Acta Endocrinol. 34: 261, 1960.

16. Pildes, R. S., Ramamurthy, R. S., Cordero, G. V., and Wong, P. W. K. Intravenous supplementation of L-Amino acids and dextrose in low birth-weight infants. $J$. Pediatr. 82: 945, 1973.

17. Rhodin, A. G. J., Coran, A. G., Weintraub, W. H., and Wesley, J. R. Total body water changes during high volume peripheral hyperalimentation. Surg. Gynecol. Obstet. 148: 196, 1979.

18. Schloerb, P. R., Friis-Hansen, B. J., Edelman, I. S. Solomon, A. K., and Moore, F. D. The measurement of total body water in the human subject by deuterium oxide dilution: With a consideration of the dynamics of deuterium distribution. J. Clin. Invest. 29: 1296, 1950.

19. Schloerb, P. R., Friis-Hansen, B. J., Edelman, I. S., Sheldon, D. B., and Moore, F. D. Measurement of deuterium oxide in body fluids by the falling drop method. J. Lab. Clin. Med. 37: 653, 1951. 